\title{
THE POTENTIAL PROTECTIVE EFFECT OF SOME HERBAL DRUGS AGAINST TETRACYCLINE INDUCED LIVER INJURY IN RATS
}

\author{
$\mathcal{B Y}$ \\ Hussein M. El-Beltagi and Soheir M. Sirag* \\ Deparments of Clinical Pharmacology and Pathology*, \\ Faculty of Medicine, Mansoura University, Egypt
}

\begin{abstract}
Hepatotoxicity is an injury to liver that is associated with impaired liver function caused by exposure to a drug or another non-infectious agent. latrogenic hepatotoxicity and their end stage liver cirrhosis are in the sphere of interest of scientists and clinicians. Long term use, especially in high dose, of tetracycline antibiotic may cause adipose liver dystrophy with accumulation of reactive oxygen species and lipid peroxidation due to mainly mitochondrial dysfunctions. Continuous efforts were done to understand the role of oxidative stress in the pathophysiology of these inflammatory liver diseases. The well documented scavenging activity (an antioxidant effect) of herbal agents namely; Silymarin, Liv-52 and Diphenyl Dimethyl Bicarboxylate (DDB) may explain the protection afforded by these substances against hepatotoxic agents. The efficacy and the mechanism of these hepatoprotective agents were judged in this study. Oral administration of tetracycline (500 $\mathrm{mg} / \mathrm{kg}$ orally) for 5 days in rats produced significant increase in both serum alanine aminotransferase (ALT) and aspartate aminotransferase (AST) levels as a markers of liver parenchymal toxicity and produced significant increase of liver malondialdhyde (MDA) level and significant depletion of both superoxide dismutase (SOD) activity and glutathione (GSH) concentration in liver homogenate compared with normal rats. Histopathologically, tetracycline treatment in the above regimen produced a picture of microvesicular steatosis. Co-administration of tetracycline with either silymarin, Liv-52 or DDB orally for 5 days produced significant decrease in serum ALT and AST and produced significant decrease in MDA and significant increase in both SOD activity and GSH content of liver homogenate compared with tetracycline alone treated group. These herbal agents produced variable degrees of improvement in histopathological changes induced by tetracycline treatment.
\end{abstract}

\section{INTRODUCTION}

Liver is an important target of drugs toxicity, xenobiotics and oxidative stress (Jaeschke et al., 2002). With the widespread use of antimicrobial agents, how-

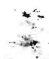

Mansoura J. Forensic Med. Clin. Toxicol. ever, hepatic injury is not an infrequent occurrence (Thiim and Friedman, 2003). Long-term use of tetracycline aritibiotics, especially high doses, may be associated with severe hepatotoxicity in form of fatty liver in both rats (Mikhail et 
al., 1996) and human (Hunt and Washington, 1994).

There are many direct and indirect mechanisms of drug-induced liver cell injury. For which, bile acid-induced liver cell injury during cholestasis, pathophysiological effects of mitochordrial dysfunction and cell damage by intracellular generation of reactive oxygen species (ROS) and nitrogen species by mitochondria. ROS are able to modulate apoptotic and necrotic cell death pathways by affecting redox-sensitive enzymes and organelles e.g. mitochondria (Jaeschke, 2000). Mitochondria are prominent targets for hepatotoxicity of many drugs (Jaeschke et al., 2002). Lipid peroxidation (LPO) is the result of an interaction between free radicals of diverse origin and unsaturated fatty acids in lipid (Poli et al., 1998). Severe impairment of mitochondrial fatty acid $\beta$ oxidation causes microvesicular steatosis characterized by accumulation of tiny lipid vesicles in the cytoplasm of hepatocytes (Fromenty and Pessayre, 1995). Several drugs inhibit $\beta$-oxidation, including tetracycline derivatives (Labbe et al., 1991).

Experimental and clinical studies suggest that xenobiotic hepatotoxicity with variable depletion of antioxidants can be avoided or ameliorated by administration of some antioxidants (Stehbens, 2003). Silymarin is a flavonoid that has been extracted from seeds and fruit of Silybum marianum and was introduced as hepatoprotective agent (Fraschini et al., 2002). Liv-52 is an indogenous drug and is reported to improve the hepatic cell function, acts as hepatic stimulant, anabolic and as a corrective and curative in many hepatic disorders including cirrhotic and toxic liver (Bharadia et al., 1986). Previous studies revealed that Diphenyl Dimethyl Bicarboxylate (DDB) could protect against liver injuries induced by hepatotoxicants e.g. carbon tetrachloride ( $\mathrm{CCl} 4)$, $\mathrm{D}$-galactosamine, acetaminophen in rats and mice (Kim et al., 1999) and clinical trials on chronic viral hepatits patients demonstrated that DDB markedly improved the impaired liver function (Zhang et al., 1987).

The aim of this study was to find out the possible prevention or improvement of tetracycline hepatoxicity by some hepatoprotective herbal agents namely, Silymarin, Liv 52 and DDB. Also, the oxidative stress parameters were measured to clarify their mechanisms of action.

\section{MATERIAL AND METHODS}

\section{Drugs used :}

1. Tetracycline Hydrochloride: it was purchased from Sied Pharmaceutical Co., Egypt.

2. Silymarin: it is a flavonoids compound. It is mixture of three structu- 
ral components; silibinin, silydianine and silychristine. Silymarin was purchased from Sedico Pharmaceutical Co., Egypt.

3. Liv 52 (India): Each Liv-52 tablet contains: Exts. Capparis spinosa, cichorium intybus, solanum nigrum, cassia occidentalis, Terminalia arjuna, Achillea milefolium, Tamarix gallica and Mandur bhasma. It was obtained from Himalaya drug Company.

4. DDB: It is Diphenyl Dimethyl Bicarboxylate (dimethyl-4,4'-dimethoxy5,6,5',6'-dimethyllene dioxybiphenyl$2,2^{\prime}$-dicarboxylate). It is a synthesized derivative of schizandrin $C$, an active component isolated from the traditional Chinese herb fractuse schizaandrea. It was obtained from Peking Pharmaceutical Factory (Beijing, China).

\section{Animals used:}

Experiments were carried out on 50 male Albino rats, weighted 150-200 gm each. The animals were housed in plastic cages at room temperature. They were allowed free access to tap water and were fed stock pallets ad libitum.

The study duration was 5 days and rats were classified into equal 5 groups (10 rats each) as follows:

Group I: Each rat in this group re- ceived orally $0.5 \mathrm{ml}$ of vehicle daily. This group was served as negative control group.

Group II: Each rat in this group received orally tetracycline hydrochloride in a dose of $500 \mathrm{mg} / \mathrm{kg}$ daily (Porokhniak, 1987). This group served as positive control group.

Group III: Each rat in this group received Silymarin orally in the dose of 50 $\mathrm{mg} / \mathrm{kg}$ daily (Boigk et al., 1997), six hours after tetracycline administration.

Group IV: Each rat in this group received Liv-52 orally in dose of $50 \mathrm{mg} / \mathrm{kg}$ daily (Patney et al., 1973), six hours after tetracycline administration.

Group V: Each rat in this group received DDB orally in dose of $50 \mathrm{mg} / \mathrm{kg}$ daily (Kim et al., 1999), six hours after tetracycline administration.

All drugs and vehicle were suspended in $1 \%$ starch gel and given by oral gavage at volume of $0.5 \mathrm{ml}$ for each rat. Hepatoprotective drugs were given six hours after tetracycline administration to avoid drugdrug interactions. On the $6^{\text {th }}$ day at the end of the study food was withdrawn overnight after the last dose of drugs treatment, then rats of all groups were sacrificed and blood was collected from carotid arteries of rats. The sera were separated 
and kept in $-20^{\circ} \mathrm{C}$ till the time of estimation of serum alanine aminotransferase (ALT), serum aspartate aminotransferase (AST)as markers of parenchymal cell damage. After rats scarification the livers were excised gently and quickly and divided into two parts. One part of each liver was preserved in $10 \%$ neutral buffered formalin for subsequent histopathological examination. The other part of each liver was used for estimation of tissue free radical in liver homogenate. Measurement of liver free radical was done via direct method by measuring malondialdehyde (MDA) or by indirect method via measuring the antioxidant enzymes; glutathione (GSH) level and superoxide dismutase (SOD) activity.

Determination of serum alanine and aspartate aminotransferase (ALT and AST) :

Serum ALT and AST were determined according to method described by Bergmeyer and Horder (1980) using the commercial spectrophotometric kits purchased from BioMérieus, France.

\section{Preparation of liver homogenate:}

- $0.5 \mathrm{gm}$ of the $2^{\text {nd }}$ part of liver tissue was homogenized with Tris- $\mathrm{HCl}$ (5 mmol/L containing $2 \mathrm{mmol} / \mathrm{L}$ EDTA PH 7.4) by sonication using soniprep 150 ultrasonic disintegrator at high power for $5 \mathrm{~min}$. in ice jacket to obtain cell homogenate (Stacey and Klaassen, 1981).
- Homogenate were centrifuged at 1000 $x \mathrm{~g}$ for $10 \mathrm{~min}$. at $4^{\circ} \mathrm{C}$. Supernatant were used for the assay of GSH, MDA and SOD after calculation of the exact wet weight per mol (Wang et al., 2005).

\section{Measurement of Malondialdehyde} (MDA) in liver homogenate (TBA test) :

The Thiobarbituric acid test (TBA) is probably the most widely used single assay for the measurement of lipid peroxidation. MDA concentration $(\mathrm{nm} / \mathrm{mg}$ wet weight) was measured according to method described by Draper and Hadley(1990).

Measurement of GSH level and SOD activity in liver homogenate:

$\mathrm{GSH}$ concentration ( $\mathrm{nM} / \mathrm{mg}$ wet weight) was determined according to method described by Beulter et al. (1963). SOD activity was measured according to method described by Nishikimi et al. (1972) which based on \% of inhibition using the ability of the enzyme to inhibit phenazine methosulphate-mediated reduction of nitroblue tetrazolium dye.

\section{Histopathological exammination:}

The fixed liver in $10 \%$ neutral buffered formalin was embedded in paraffin wax; 5 $\mu \mathrm{m}$ section were cut and stained with haematoxylin and Eosin (HX \& E ) using conventional method. Liver section was examined for signs of hepatotoxicity induced by tetracycline and for signs of 
improvement by treatment with Sylimarin, Liv 52 or DDB concomitantly with tetracycline treatment.

\section{RESULTS}

Biochemical effects of Silymarin, Liv52 or DDB treatment on tetracycline induced liver injury :

As shown in table (1) oral administration of tetracycline at a dose $500 \mathrm{mg} / \mathrm{kg}$ orally for 5 days in rats produced significant $(P<0.001)$ increase in both serum ALT and AST $(22.3 \pm 2.1$ and $45.2 \pm 3.8$ IU/L, respectively) compared with normal rats $(11.3 \pm 1.01$ and $31.3 \pm 2.2$; respectively).

Coadministration of tetracycline in same dose regimen with either Silymarin (50 mg/kg/day) or Liv-52 (25 mg/ $\mathrm{kg} /$ day) or DDB (50 mg/ kg/day) orally for 5 days produced significant $(\mathrm{P}<0.01)$ decrease in serum ALT and AST $(15.1 \pm 1.4$ and $38.1 \pm 1.7$ or $14.2 \pm 1.2$ and 36.2 or 13.8 \pm 1.3 and $35.5 \pm 2.8$, respectively) compared with rats received tetracycline alone for 5 days.

As shown in table (2) oral administration of tetracycline in above mentioned dose and duration to rats produced significant increase of liver MDA $(\mathrm{P}<0.018)(5.6$ $\pm 0.37 \mu \mathrm{M} / \mathrm{mg}$ wet weight) and significant depletion of both SOD activity $(\mathrm{P}<0.001)$ and GSH concentration $(\mathrm{P}<0.05)(25.43 \pm$
0.83 and $45.25 \pm 1.72$, respectively) in liver homogenate compared with normal rats $(4.33 \pm 0.33,69.75 \pm 0.83$ and $59.42 \pm 1.14$, respectively).

Coadministration of tetracycline orally with either Silymarin or Liv-52 or DDB orally in above mentioned regimen to rats produced significant restore $(\mathrm{P}<0.001)$ of liver SOD activity $(53.38$ \pm 1.98 or $58.01 \pm 1.18$ or $56.72 \pm 2.3$, respectively) and significant increase $(P<0.006-0.001)$ for liver GSH concentration $(53.39 \pm 2.03$ or $54.18 \pm 0.83$ or $59.46 \pm$ 1.03, respectively) and produced significant decrease $(P<0.025-0.002)$ of MDA level $(4.51 \pm 0.26$ or $4.09 \pm 0.17$ or $4.4 \pm$ 0.25 , respectively) in liver homogenate compared with tetracycline alone treated group (Table 2).

Histopathological changes of Silymarin, Liv-52 or DDB treatment on Tetracycline induced liver injury:

Histopathological examination of liver lobules and portal tract in rats which received tetracycline alone $(500 \mathrm{mg} / \mathrm{kg} /$ day for 5 days) showed degeneration of peripheral hepatocytes in form of marked vacuolization with scattered signet ring cells (picture of microvesicular and macrovesicular steatosis) (Fig. 2) and showed focal necrosis of intralobular hepatocytes, the site of which is indicated by accumulation of inflammatory cells (Fig. 3). Portal tract showed severe to moderate mono- 
nuclear cells infilteration with spillover hepatic parenchyma (Fig. 4) .

Administration of Silymarin for 5 days concomitantly with tetracycline orally in the above regimen produced variable degrees of improvement in histological changes induced by tetracycline, in the form of focal necrosis of hepatocytes, mild degree of degeneration in form of hydrobic degeneration and mild portal inflammation (Fig. 5). There was a picture of normal liver cells in about $30 \%$ of these treated rats.

This improvement was markedly seen in the groups that received Liv-52 orally for 5 days together with tetracycline compared with histopathological changes in tetracycline alone treated group. There were milder lesions in form of focal degenerative changes with mild portal inflammation in $60 \%$ of rats in this treated group (Fig. 6).

While co-administration of DDB with tetracycline orally for 5 days produced complete improvement in histological changes induced by tetracycline alone administration, so the histological picture of these rat livers was near normal histological appearance in about $50 \%$ of treated rats (Fig. 7) with focal microvesicular steatosis and mild to moderate portal tract inflammation in the other $50 \%$ of treated rats.

\section{DISCUSSION}

The xenobiotic hepatotoxicity ranging from a subclinical anicteric state to severe necroinflammatory hepatitis and cirrhosis depends on the nature, dosage and duration of exposure to the xenobiotic and the available antioxidant defence in the liver. Hepatic metabolisms of biological toxins, industrial poisons and medicinal agents involves disturbed hepatic cell biochemistry with augmented generation of reactive oxygen species and free radicals and redox imbalance with secondary change to proteins, nucleic acids, lipids and carbohydrates (Stehbens, 2003).

In the present study, some herbal hepatoprotective agents namely; Silymarin, Liv-52 and DDB were used to assess their potential protective effect against tetracycline hepatotoxicity.

In this study administration of tetracycline for 5 days caused disorder of the liver functions as evidenced by significant increasing activity of serum ALT and AST. Elevations in serum enzyme levels (ALT and AST) were taken as indicators of liver injury which is due to pronounced dystrophic changes of hepatocytes, followed by membranes injury that results in increase of cell enzymes discharge (Bjornsson and Olsson, 2005). Moreover, MDA level was increased significantly in liver homogenate manifesting an increase of 
primary and secondary products of lipoperoxidation (LPO) in homogenates of the liver. Meanwhile, tetracycline produced significant reduction of SOD activity and GSH levels in liver homogenates that reflect the level of natural interior free radical scavengers, which are known to serve as antioxidative enzymes in cells (Pessaye et al., 2001).

These results were consistent with results of previous studies. Shakaun and Visotski (1984) and Shakaun et al., (1985) reported that toxic doses of tetracycline produced activation of LPO and malondialdehyde in the liver homogenate and elevation of alanine and aspartate aminotransferase enzymes in the blood of albino rats. Moreover, Porokhniak (1987), mentioned that tetracycline caused disorder of liver functions evident from elevation of transaminases in the rat blood serum. Furthermore, in human study, Hunt and Washington (1994), found that tetracycline induced hepatitis, characterized by prolonged jaundice, severe pruritis and moderate increased transaminase values in female patients. Recently, Kaplowitz (2004) stated that hepatic injury induced by high dose of tetracycline was associated with moderate elevation of the ALT and AST levels.

As regard the histopathological changes induced by tetracycline in this study there was picture of microvascular steatosis.
This data was consistent with the previous studies. Long term chemotherapy with high doses of tetracycline may cause adipose liver dystrophy. Accumulation of adipose in the liver, induced by tetracycline, is the result of oxidation of cell membrane phospholipids which causes the accumulation of toxic hydroperoxides and other products of LPO in the liver (Shakaun and Visotski, 1984; Porokhniak, 1987; Silva and Rocha, 1995).

Furthermore, Maddrey (2005), reported that tetracycline is one of the drugs which is responsible for microvesicular steatosis in liver with the presence of small fatty vesicles filling the cytoplasm of the hepatocyte (foamy hepatocyte). This lesion may be attributed to interference with $\beta$ oxidation of fatty acid by mitochondria. Moreover, Machado et al., (2003) showed intense diffuse vacuolization with many small, medium and large vacuoles in hepatocytes and dilated sinusoids, foci of necrosis and foci of inflammation after tetracycline treatment. Recently, Kaplowitz (2004), in human study, said that high dose of tetracycline showed microvesicular steatosis on liver biopsy.

In this study administration of either Silymarin, Liv-52 or DDB with tetracycline produced significant lowering of ALT and AST levels and MDA level, while it produced significant restore or increase of hepatic GSH level and SOD activity 
compared with that in the group received tetracycline only.

The hepatoprotective effect of the above mentioned herbal drugs in the present study was consistent with several experimental and clinical studies, which demonstrate well-pronounced hepatoprotective effects against a wide variety of hepatotoxins (Halim et al., 1997). Mechanistic studies in rodents and in cell culture have shown that Silymrin is a strong antioxidant capable of scavenging free radicals (Basaga et al., 1997) which may be due to its silybin's chemical structure (Medina and Moreno-Otero, 2005). It has been shown in rats that silibinin protects neonatal hepatocytes from cell damage produced by many hepatotoxins which develop oxidative stress (Campos et al., 1989; Davila et al., 1989). The oxidative stress is associated with a reduction in the amount of reduced glutathione (GSH) in the liver; which exerts important protective activity against chemically induced oxidative stress (Valenzuela et al., 1985). In rats treated with Silymarin, a significant increase in the amount the GSH contained in the liver was found (Valenzuela et al., 1989). Furthermore, it has been shown that Silymarin protects rat liver mitochondria and microsomes in vitro against the formation of lipid peroxides induced by various agents (Bindoli et al., 1977).

Also Silymarin acts as cell membrane stabilizers and permeability regulators that prevent hepatotoxic agents from entering hepatocytes (Fraschini et al., 2002). The protective effect of Silymarin is mediated by the inhibition of lipid peroxidation and the modulation of heptocyte $\mathrm{Ca}^{2+}$ content seems to play a crucial role. The stimulation of protein synthesis is an important step in the repair of hepatic injury and is essential for restoring structural protein and enzymes damaged by hepatotoxins (Farghali et al., 2000).

Patney et al., (1973) found that rats receiving Liv-52 was protected against tetracycline induced fatty degeneration. Liv-52 is reported to improve the hepatic cell functions, act as a hepatic stimulant, anabolic and as a corrective and curative in many hepatic disorders (Bharadia et al., 1986). Porokhniak (1987) reported that Liv-52 removed cytolytic effect of tetracycline on the liver cell membranes by decreasing the ALT and AST levels and decreasing perioxidation product of tetracycline namely; MDA and increasing free radicals scavengers GSH and SOD which was decreased by tetracycline toxication. Moreover, Dhumal et al., (1989) reported that oral administration of Liv- 52 to experimental animals provided considerable protection against liver damage by $\mathrm{CCl}_{4}$. Furthermore, De Silva et al., (2003) said that Liv-52 showed an antioxidant effect in $\mathrm{CCl}_{4}$ induced liver damage by increasing free radical scavengers (GSH and 
SOD) and decreasing MDA level. This antioxidant activity may be initiated from Liv-52 herbal ingredient of natural complexes, so the mechanism seems to be similar to that of silymarin (Huseini et al., 2005).

The protective effect of DDB on chemically induced damages was studied in primary culture of rat hepatocytes ( $\mathrm{Fu}$ and Liu, 1992). They showed that DDB efficiently protected the hepatocytes against $\mathrm{CCl}_{4}$ and D-galactosamine induced damages. Membrane lipid peroxidation (MDA) formation and ALT released from the hepatocytes were markedly decreased.

DDB administration decreased the hepatic fatty degeneration induced by repeated ethanol treatment in rats and inhibited MDA formation in liver homogenates (Kim et al., 1999). In addition $\mathrm{Li}$ and $\mathrm{Li}$ (2001), reported that the elevation of serum ALT, liver MDA content and mitochondria potential injury induced by THA (Tetrahydroacridine) were significantly inhibited by DDB pretreatment. Furthermore, Park et al., (2005) reported that DDB pretreatment effectively prevented increases in plasma aminotransferases in rats exposed to $\mathrm{CCl} 4$ and histologically it abrogated the central necrosis, hepatocyte degeneration and inflammation induced by $\mathrm{CCl}$. This protective effect of DDB may attribute its effect against mitochondria.
EL-Sawy et al., (2002) found that in chemically injured rat livers there were a significant decrease in the elevated levels of liver enzymes and significant increase in reduced glutathione, glutathione peroxidase and glutathione reductase and a significant decrease in MDA level after DDB administration. The histopathology examination showed improvement with DDB administration.

In liver injury model with oxidative stress in rats, the oral administration of DDB resulted in alleviation of the oxidative stress status as observed by significant increments in the antioxidant enzymes (glutathione-S-transferase, glutathione peroxidase and catalase) and reduced glutathione concomitant with significant decrements in liver transaminases; ALT and AST levels. (ELBeshbishy, 2005).

Moreover, Ip et al., (2000) and Gao et al., (2005) reported that oral administration of DDB in mice markedly reduced the elevated serum ALT, AST and directly protected hepatocyte DNA from oxidative damage.

In clinical study, Hurber et al., (2004) reported about 13 patients with persistently elevated ALT levels and treated with DDB, ALT rapidly normalized in 12/13 patients and remained normal during treatment. 
In conclusion, the herbal drugs used in this study exerted a variable degrees of hepatoprotection against the potential hepatic injury induced by tetracycline antibiotic through amelioration of eleva- tion of liver cellular enzymes (ALT and AST) and free radicals of lipid peroxidation (MDA) and via elevation of endogenous antioxidative liver enzymes (SOD and GSH) . 
Table (1): Serum Alanine Aminotransferase (ALT) and Serum Aspartate Aminotransferase (AST) after administration of Silymarin, Liv-52 or DDB with or without Tetracycline in Albino rats.

\begin{tabular}{|c|c|c|}
\hline Groups $(n=10)$ & $\begin{array}{c}\mathrm{ALT}(\mathrm{IU} / \mathrm{L}) \\
\mathrm{M} \pm \mathrm{SE}\end{array}$ & $\begin{array}{c}\mathrm{AST}(\mathrm{IU} / \mathrm{L}) \\
\mathrm{M} \pm \mathrm{SE}\end{array}$ \\
\hline Negative control & $11.3 \pm 1.01$ & $31.3 \pm 2.2$ \\
\hline Tetracycline alone ${ }^{(a)}$ & $\begin{array}{l}22.3 \pm 2.1 \\
P<0.001\end{array}$ & $\begin{array}{l}45.2 \pm 3.8 \\
\mathrm{P}<0.001\end{array}$ \\
\hline Tetracycline + Silymarin ${ }^{(b)}$ & $\begin{array}{l}15.1 \pm 1.4 \\
P_{1}<0.01\end{array}$ & $\begin{array}{l}38.1 \pm 1.7 \\
\mathrm{P}_{1}<0.01\end{array}$ \\
\hline Tetracycline + Liv-52 ${ }^{\text {(c) }}$ & $\begin{array}{l}14.2 \pm 1.2 \\
P_{1}<0.01\end{array}$ & $\begin{array}{l}36.2 \pm 2.3 \\
P_{1}<0.01\end{array}$ \\
\hline Tetracycline $+\mathrm{DDB}^{(\mathrm{d})}$ & $\begin{array}{l}13.8 \pm 1.3 \\
\mathrm{P}_{1}<0.01\end{array}$ & $\begin{aligned} 35.5 \pm 2.8 \\
\mathrm{P}_{1}<0.01\end{aligned}$ \\
\hline
\end{tabular}

(a) Tetracycline dose : $500 \mathrm{mg} / \mathrm{kg} / \mathrm{day}$

(b) Silymarin dose :50 mg/kg/day

(c) Liv-52 dose : $25 \mathrm{mg} / \mathrm{kg} /$ day

(d) $D D B$ dose : $50 \mathrm{mg} / \mathrm{kg} /$ day

$M \pm S E=$ Mean \pm Standard Error

$P=$ Significance of difference between tetracycline alone treated group and normal control groups.

$P_{1}=$ Significance of difference between Silymarin, Liv-52 or DDB with tetracycline treated group and tetracycline alone treated group. 
Table (2) : Serum Malondialdehyde (MDA), Superoxide Desmutase (SOD) and Serum Glutathione (GSH) after administration of Silymarin, Liv-52 or DDB with or without Tetracycline in Albino rats.

\begin{tabular}{|c|c|c|c|}
\hline Groups $(n=10)$ & $\begin{array}{c}\text { MDA } \\
\text { (nM/mg wet } \\
\text { weight) }\end{array}$ & $\begin{array}{c}\text { SOD } \\
\% \text { inhibition }\end{array}$ & $\begin{array}{c}\text { GSH } \\
\text { (nM/mg wet } \\
\text { weight) }\end{array}$ \\
\hline Negative control & $4.33 \pm 0.333$ & $69.75 \pm 0.836$ & $59.42 \pm 1.14$ \\
\hline Tetracycline alone $^{(e)}$ & $\begin{array}{l}5.6 \pm 0.37 \\
P<0.018\end{array}$ & $\begin{array}{c}25.43 \pm 0.83 \\
P<0.001\end{array}$ & $\begin{array}{c}45.25 \pm 1.72 \\
P<0.05\end{array}$ \\
\hline Tetracycline + Silymarin ${ }^{(f)}$ & $\begin{array}{c}4.51 \pm 0.26 \\
P_{1}<0.025\end{array}$ & $\begin{array}{c}53.38 \pm 1.98 \\
P_{1}<0.001\end{array}$ & $\begin{array}{c}53.39 \pm 2.03 \\
P_{1}<0.006\end{array}$ \\
\hline Tetracycline + Liv- $52^{(g)}$ & $\begin{array}{l}4.09 \pm 0.17 \\
P_{1}<0.002\end{array}$ & $\begin{array}{c}58.01 \pm 1.18 \\
P_{1}<0.001\end{array}$ & $\begin{array}{c}54.18 \pm 0.83 \\
P_{1}<0.001\end{array}$ \\
\hline Tetracycline + DDB ${ }^{(\mathrm{h})}$ & $\begin{array}{l}4.4 \pm 0.25 \\
P_{1}<0.014\end{array}$ & $\begin{array}{c}56.72 \pm 2.3 \\
P_{1}<0.001\end{array}$ & $\begin{array}{c}59.46 \pm 1.03 \\
P_{1}<0.001\end{array}$ \\
\hline
\end{tabular}

(e) Tetracycline dose: $500 \mathrm{mg} / \mathrm{kg} /$ day

(f) Silymarin dose : $50 \mathrm{mg} / \mathrm{kg} /$ day

(g) Liv-52 dose : $25 \mathrm{mg} / \mathrm{kg} /$ day

(h) $D D B$ dose : $50 \mathrm{mg} / \mathrm{kg} /$ day

$M \pm S E=$ Mean \pm Standard Error

$P=$ Significance of difference between tetracycline alone treated group and normal control groups .

$P_{1}=$ Significance of difference between Silymarin, Liv-52 or DDB with tetracycline treated group and tetracycline alone treated group. 


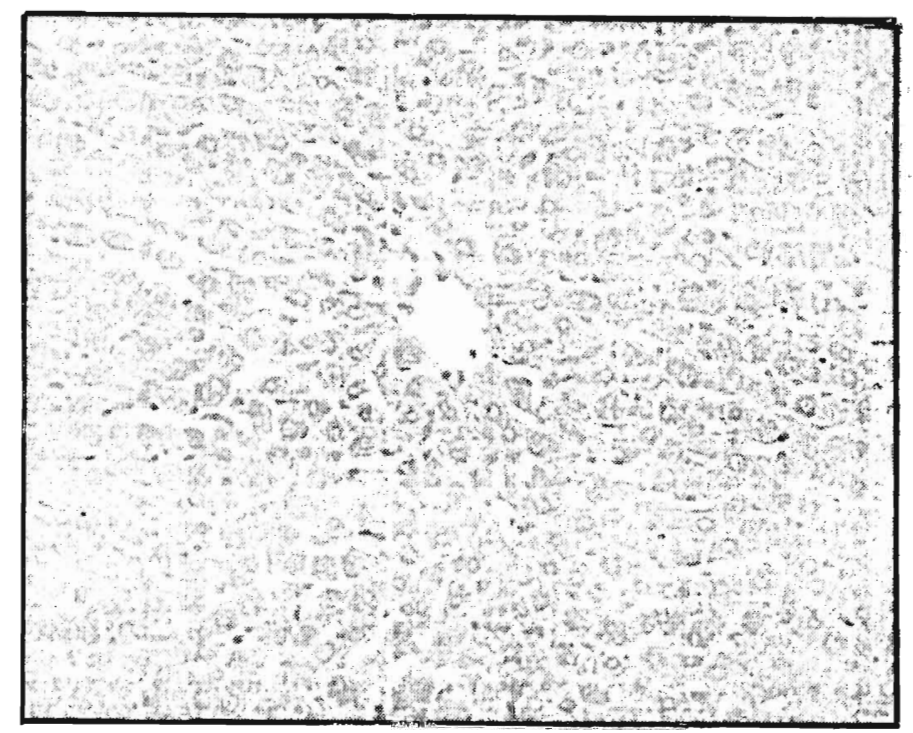

Fig. (1) : Normal rat liver showing normal liver architectures. (HX\&E x 100)

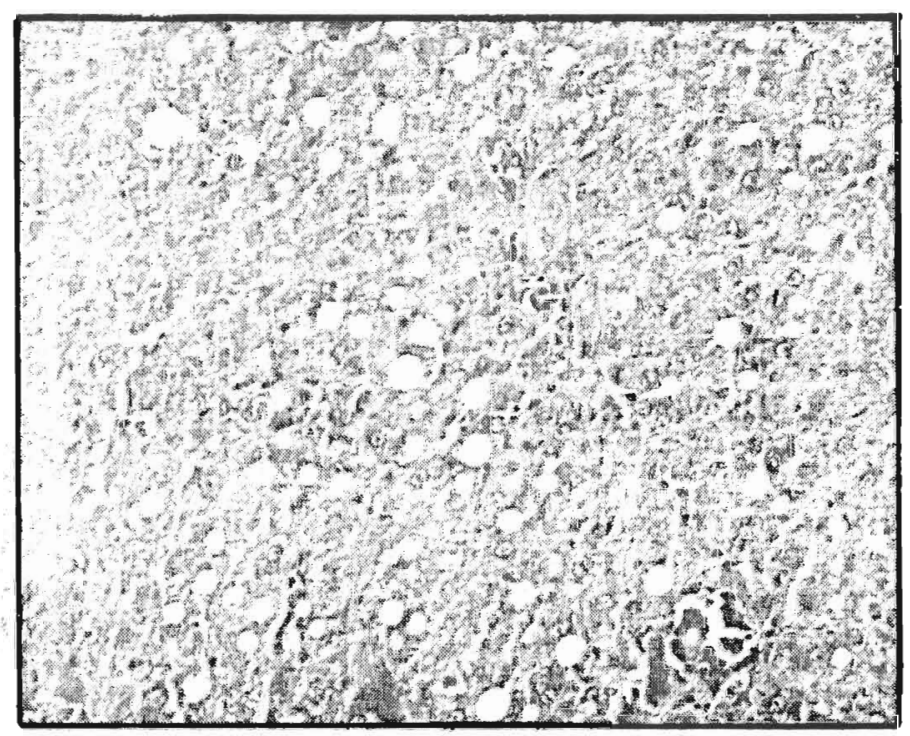

Fig. (2) : Rat liver treated with tetracycline alone showing marked micro- and macrovesicular steatosis.

(HX\&E x 100) 


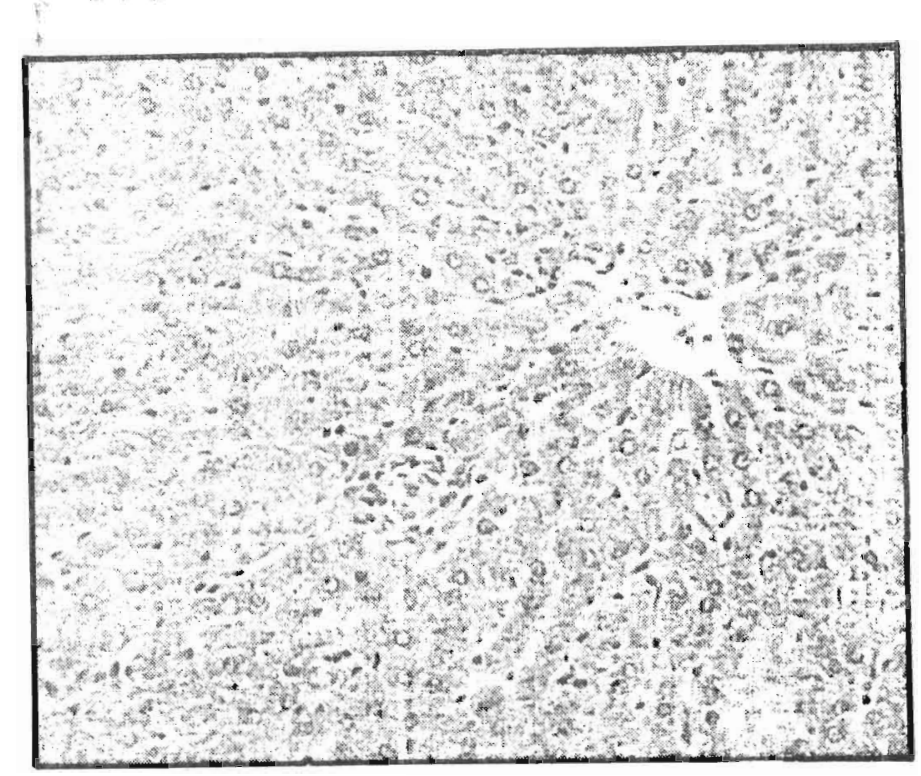

Fig. (3) : Rat liver treated with tetracycline alone showing focal necrosis of intralobular hepatocytes.

(HX\&E x 150)

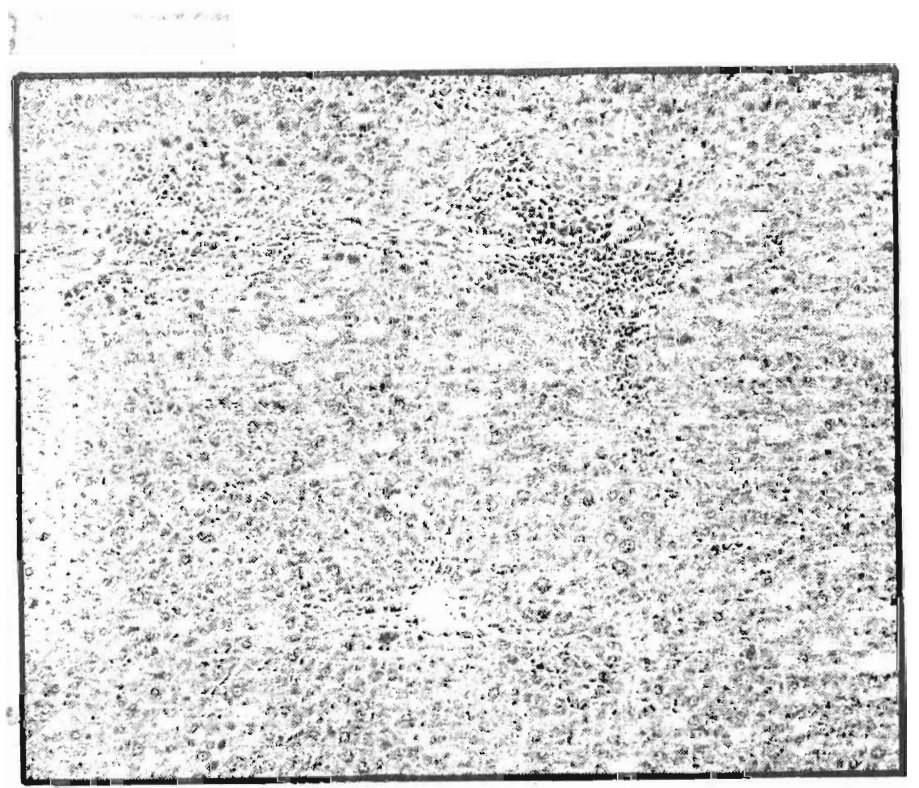

Fig. (4) : Rat liver treated with tetracycline alone showing severe to moderate mononuclear infiltration in portal tract.

(HX\&E x 100) 


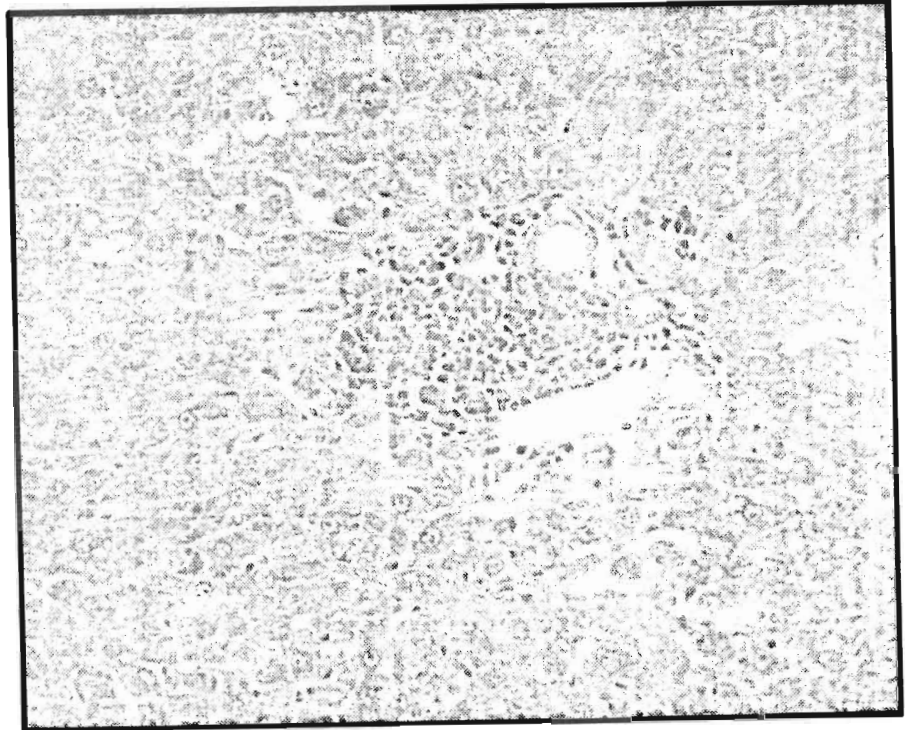

Fig. (5) : Rat liver treated with tetracycline concomitantly with Silymarin showing mild improvement of steatosis induced by tetracycline.

(HX\&E x 150)

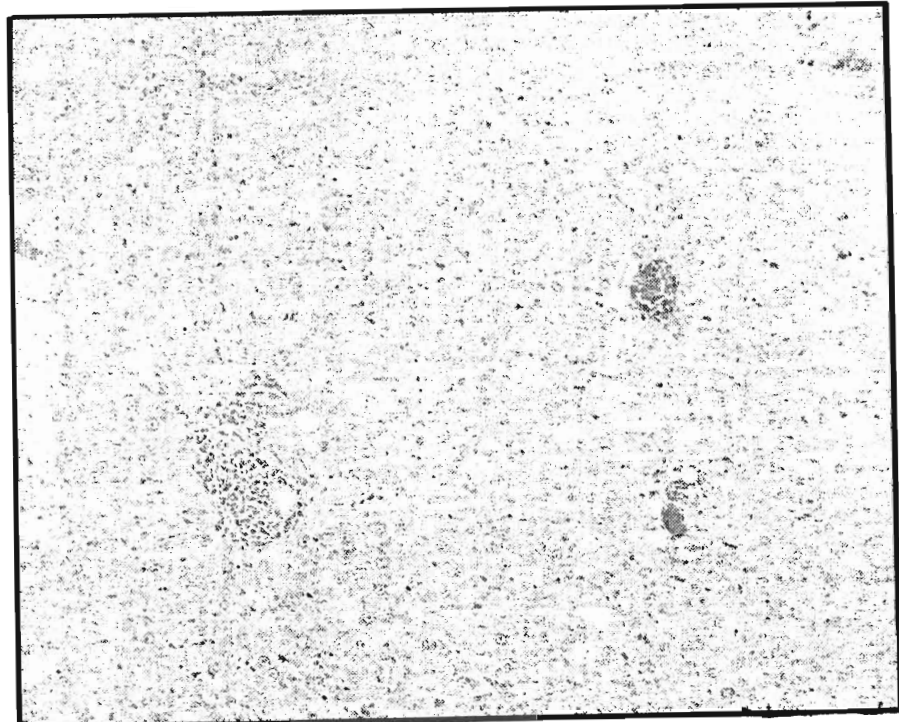

Fig. (6) : Rat liver treated with tetracycline concomitantly with Liv-52 showing more improvement of steatosis with mild portal inflammation in about $60 \%$ of treated rats.

(HX\&E x 100) 


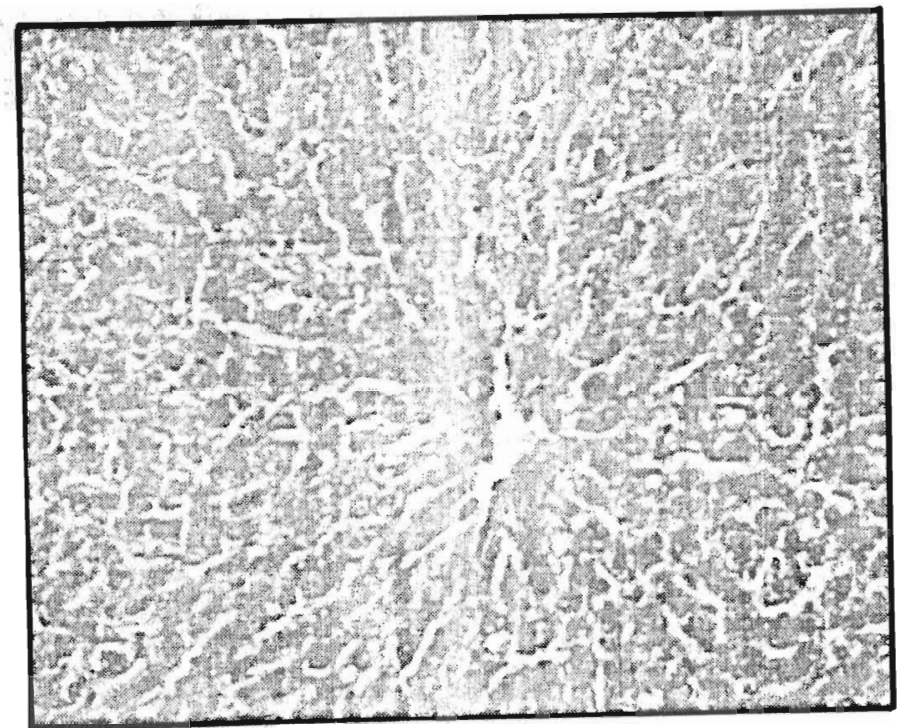

Fig. (7) : Rat liver treated with tetracycline concomitantly with DDB showing picture of normal liver (complete improvement in $50 \%$ of treated rats in this group).

(HX\&E x 160) 


\section{REFERENCES}

Basaga, H.; Poli, G.; Tekkaya, C.; et al. (1997): "Free radical scavenging and antioxidative properties of silibin complexes on microsomal lipid peroxidation". Cell Biochem. Funct., 15:2733.

Bergmeyer and Horder (1980): Clin. Chem. Acta $105147 \mathrm{~F}$ international federation of clinical chemistry, Scientific Committee, J. Clin. Chem. Clin. Biochem. 18:521-534 .

Beulter, E.; Duron, O. and Kelly, B. M. (1963) : "Improved method for the determination of blood glutathione". J. Lab. Chem. Med., 61(5):882.

Bharadia, G. R.; Kukade, A. L.; Kulkarni, A. S. and Rathod, I. M. (1986) : "Liv-52 in the management of various hepatic disorders - A study of 53- cases." Probe XXV (3): 277 - 280.

Bindoli, A.; Cavallini, A. L. and Siliprandi, N. (1977): "Inhibitory action of silymarin of peroxide formation in rat liver mitochondria and microsomes". Biochem. Pharmacol., 26:2405-9.

Bjornsson, E. and Olsson, R. (2005) : "Outcome and prognostic markers in severe drug-induced liver disease". Hepatology, 42:481-9.
Boigk, G.; Stroedter, L.; Herbest, H.; et al. (1997) : "Silymarin retards collagen accumulation in early and advanced biliary fibrosis secondary to complete bile duct obliteration in rats". Hepatology, 26:643-9.

Campos, R.; Garrido A. and Guerra A. (1989) : "Silybin dihemisuccinate protects against glutathione depletion and lipid peroxidation induced by acetaminophen on rat liver". Planta Med., 55:417-9.

Davila, J. C.; Lenherr, A. and Acosta, D. (1989) : "Protective effect of flavonoids on drug-induced hepatotoxicity in vitro". Toxicology, 57:267-86.

De Silva, H. A.; Saparamadu, P. A.; Thabrew, M. I.; Pathmeswaran, A.; Fonseka, M. M. and De Silva, H. J. (2003) : "Liv-52 in alcoholic liver disease: a prospective, controlled trail". J. Ethnopharmacol., 84 (1): 47-50.

Dhumal, M. S.; Mane, I. H. and Patel, S. S. (1989) : "Effect of Liv-52 on carbon tetrachloride". Ind. J. Pharmacol., 21:96-9.

Drapper, W. and Hadley, M. (1990) : "Indirect determination of oxygen free radicals". Methods Enzymol.,186,421- 431.

El-Beshbishy, H. A. (2005) : "The effect of dimethyl dimethoxy biphenyl dicarboxylate (DDB) against tamoxifen-induced liver injury in rats: DDB use is curative or 
protective". J. Biochem. Mol. Biol., 3 (3): 300-6.

El-Sawy, S. A.; El-Shafey, A. M. and EL-Bahrawy, H. A. (2002) : "Effect of dimethyl diphyl bicarboxylate on normal and chemically-injured liver". East Mediterr. Health J., 8(1): 95-104.

Farghali, H.; Kamenikova, L.; Hynie, S.; et al. (2000) : "Silymarin effects of intracellular calcium and cytotoxicity: a study in perfused rat hepatocytes after oxidative stess injury". Pharmacol. Res., 41:147-54.

Fraschini, F.; Demartini, G. and Esposti, D. (2002) : "Pharmacology of silymarin; abstract and introduction pharmacodynamics". Clinical Drug Investigation, 22(1): 51-65.

Fromenty, B. and Pressayre, D. (1995): "Inhibition of mitocherdrial B-oxidation as a mechanism of hepatotoxicity". Pharmacol. There., 67:101-154.

Fu, T. and Liu, G. (1992) : "Protective effects of biophenyl dimthyl dicaboxylate on damage in isolated rat hepatocytes induced by carbon tetrachloride and Dgalactosamine". Biomed. Environ. Sci., 5 (3):185-94

Gao, M.; Zhang, J. and Liu, G. (2005): "Effect of diphenyl dimethyl bicarboxylate on conacanavalin-A induced liver injury in mice". Liver International,25(4):904-912.

Halim, A. B.; El-Ahmady, O.; HassabAllah, S.; et al. (1997) : "Biochemical effect of antioxidants on lipid and liver function in experimentally-induced liver damage. Ann. Clin. Biochem., 34:656-663.

Huber, R.; Hockenjos, B. and Blum H. E. (2004) : "DDB treatment of patients with chronic hepatitis". Hepatology, 39 (6):1732-3.

Hunt, C. M. and Washington, K. (1994) : "Tetracycline-induced bile duct paucity and prolonged cholestasis". Gastroenterology, 107(6): 1844-7.

Huseini, H. F.; Alavian, S. M.; Heshmat, R.; Heydari, M. R. and Abolmoali, K. (2005) : "The efficacy of liv-52 on liver cirrhotic patients: a randomized doubleblind, placebo- controlled first approach". Phytomedicine, 12(9): 619-24.

Ip, S. P.; Yiu, H. Y. and Ko, K. M. (2000) : "Differental effect of schisandrin B and dimethyl diphenyl bicarboxylate (DDB) on hepatic mitochondrial glutathione redox status in carbon tetrachloride intoxicated mice". Mol. Cell Biochem., 205(1-2):111-4.

Jaeschke, H. (2000) : "Reactive oxygen and mechanisms of inflammatory liver in- 
jury". J. Gastroenterology and Hepatology, 15 (7):718-724.

\section{Jaeschke, H.; Gores, G. J.; Cederbaum,} A. I.; et al.; (2002) : "Mechanism of Hepatotoxicity". Toxicological Sciences, 65:166176.

Kaplowitz, M. (2004) : "Drug-induced liver injury". Clin. Infect. Dis., 38: Suppl 2:544-548.

Kim, S. N.; Kim, S. Y.; Yim, H. K.; Lee W. Y.; et al.; (1999) : "Effects of dimethyl4, 4-dimthoxy-5, 6, 5', 6'-dimethylenedioxybipheny; -2, 2'-dicarboxylate (DDB) on chemical-induced liver injury". Biol., Pharm. Bull., 22(1):93-5.

Labbe, G.; Fromenty, B.; Freneaux, E.; et al. (1991) : "Effects of various tetracycline derivatives on in vitro and in vivo Boxidation fatty acids egrees of triglycrides from the liver, accumulation of hepatic triglycerides and mortality in mice". Biochem. Pharmacol., 41: 638-641.

Li, Y. and Li, Y. (2001) : "Effect of dimethyl cliphenyl bicarboxylate (DDB) on 9amino 1,2,3,4- tetrahydroaridine-induced hepatotoxicity in mice". Yao Xue Bao., 36 (7): 493-7 (Article in Chinese).

Machado, A. L. D.; da Silva, Brandao, A. A. H.; Monteiro da Silva, L. D. M. and da Rocha, R. F. (2003): "Influence of tetra- cycline in the hepatic and renal development of rat's offspring". Braz. Arch. Biol. Technol., No, (1).

Maddrey, W. C. (2005) : "Drug-induced hepatotoxicity". J. Clin. Gastroentrol., 39 (4) (suppl 2): 583-9.

Medina, J. and Moreno-otero, R. (2005) : "Pathophysiological basis for antioxidant therapy in chronic liver disease". Drugs, 65(17):2445-61.

Mikhail, T. H.; Nicole, W. G.; Ibrahim, K. H.; Salama, S. H. and Emam, M. (1996): "Abnormal zinc and copper metabolism in hepatic steatosis". Boll. Chem. Farm, 135 (10):591-7.

Nishikimi, M.; Roa, M. A. and Yogi, K. (1972) : "The occurrence of superoxide anion in the reaction of reduced phenazine methosulfate and molecular oxygen". Biochem. Biophy. Res. Commun.,46:849.

Park, E. Y.; Ki, S. H.; Ko, M. S.; Kim, C. W.; Lee, M. H.; Lee, Y. S. and Kim S. G. (2005) : "Garlic oil and DDB, comprised in a pharmaceutical composition for the treatment of patients with viral hepatitis , prevents acute liver injuries potentiated by glutathione deficiency in rats". Chemico-Biological Interactions, 155:82-96.

Patney, N. L.; Jasuja, R. K. and Kumar, A. (1973) : "Liv-52- A new therapeutic 
agent in the management of steatorrhoea of liver cirrhosis of the liver". J. Res. Ind. Med., (3) 28.

Pessayre, D.; Berson, A.; Fromenty, B. and Mansouri, A. (2001): "Mitochondria in sleatohepatitis". Semin. Liver Dis., 21:57-69.

Poli, G.; Cutrin, J. C. and Biasif, F. (1998) : "Lipid peroxidation in the reperfusion injury of the liver". Free Radic. Res., 28:547-51.

Porokhniak, L. A. (1987) : "Aclion of hepatoprotective agents in a tetracycline lesion of the liver". Antibiot. Med. Biotekhnol., 32(4):282-285 (Article in Russian).

Shakaun, N. P. and Visolski, I. U. (1984) : "Scasonal characteristics of the effecliveness of vilamin E and sodium selcnate in tetracycline-induced liver damage". Antibiotiki, 29(11): 856-61.

Shakam, N. P.; Olcinilk, A. N.; Shaman'ko, W. and Koval' Chuk, S. F. N.A. (1985) : "Effects of ethyl alcohol on bile production and lipid peroxidation in tetracycline induced liver lesions". Antibiot. Med. Biotekhnal., 30 (2):115-8.

Silva, J. R. O. and Rocha, R. F. (1995) : "Efeitos do cloridrato de tetraciclina $\mathrm{cm}$ fetos de ratas tratadas com". O antibiotico, Rev. Odontal., 24:109-115.
Stacey, N. H. and Klaassen, C. D. (1981) : "Conner toxicity in isolated rat hepalocyles". Toxical. Appl. Pharmacol., 58:211-220.

Slehbens, W. E. (2003) : "Oxidalive stress, loxic hepalitis and molecular pathology emphasis on zinc. Experimental and Molecular Palhology". 75 (3):265276.

Thiim, M. and Fricdman, L. S. (2003) : "Hepaloxicity of anlibiolics and antifungals". Clin. liver Dis., 7 (2) :381-99.

Valenzucla, A.; Aspillaga, M.; Vial, S.; ct al. (1989) : "Scleclivity of silymarin on the increase of the glutathione content in different lissues of the ral". Planta. Med., 55:420-2.

Valenzucla, $\Lambda . ;$ Lagos, C.; Schmidt, K.; ct al. (1985): "Silymarin protection against hepalic lipid peroxidation induced by acule ethanol intoxication in the rat". Biochem. Pharmacol., 34: 12.

Wang, H.; Wei, W.; Zhang, S. Y.; Shen, Y. X.; Wang, N. P.; Yue, L. and Xu, S. Y. (2005) : "Melatonin-selenium nanoparticles prolects liver against immunological injury induced by bacillus CalmetleGuerin and lipopolysaccharide". Acta Pharmacol. Sin., 26 (6):745 -52.

Zhang, Y. X.; Yu, H. Q.; Shi, J. Z.; Qi H. 
B.; Dong, Z. H. and Xu, H. Y. (1987): abnormal laboratory parameters in "The therapeutic effect of biphenyl- chronic hepatitis". J. Tradit. Chin. Med., 7 dimethyl-dicarboxylate (DDB) on certain $\quad(2): 137-8$. 


\title{
دراسة إمكانية حماية بعض العقاقير العشبية لكبد الجرذان البيضاء الهحدث به الإبابة بالتتراسيكلين العية العية
}

\author{
المشتركون فى البحث
}

د.حسين محمود البلتاجى أ. د. سفير هحمد سراج*

من أتسام الفارماكولوجى الإكلينيكى والباثولوجى* - كلية الطب - جامعة المنصورة

تحدث إصابة الكبد - والتى تؤدى إلى تصور فى وظائفه - إما نتيجة لسمية بعض الأدوية أو عوامل أخرى معدية أو غير معدية. إن سمية

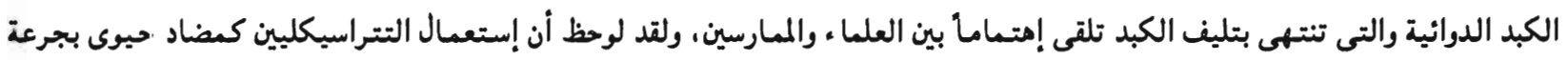

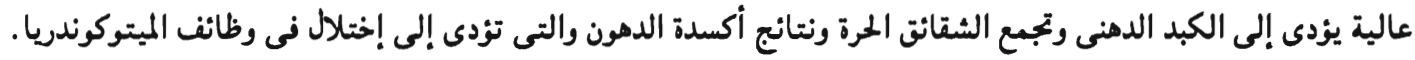

ولقد أجرى هذا البحث لدراسة تأثير بعض العقاتير عشبية المصدر مثل السليمارين، ليف -52 ، د.د.ب لحماية الكبد ضد الإصابة المحدثة بالتتراسيكليين وأيضا ، دراسة ميكانيكية حدوث هذه الحماية إن أمكن.

لوحظ أن إعطاء التتراسيكليين ( 500 مجم/كجم) بالفم ولمدة 5 أيام للجرذان تد أحدث إرتفاعا ملحوظاً فى إنزيعات الكبد نى مصل الدم

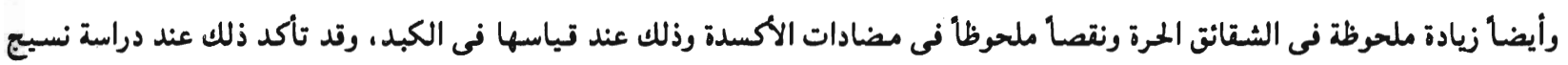
الكبد باثولوجيا.

وقد لوحظ أن معالجة الجرذان بأى من السليمارين أوليف - 52 أو د.د.ب مع التتراسيكلبين لمدة 5 أيام بالفم أحدث نقصاً ملحوظاً فى إنزيات الكبد فى مصل الدم ونقصاً ملعوظاً أيضاً فى معدل الشقائق الحرة، كسا أحدث زيادة ملحوظة فى مضادات الأكسدة فى الكبد مقارنة بالحيوانات المعالجة بالتتراسيكليين نقط. يستخلص من هذا البحث أن هذه العقاتبر تد أحدثت درجة من الحماية للكبد ضد الإصابة بسمية التتراسبكليين سواء بفحص النسيج

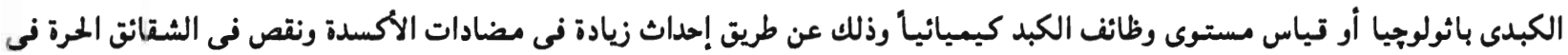

